\title{
Efeito da salinidade em características biométricas e na nutrição de Pinus taeda em Neossolo Litótico húmico
}

\author{
Shizuo Maeda(1), Helton Damin da Silva(1) e Antonio Francisco Jurado Bellote(1) \\ (1)Embrapa Florestas, Estrada da Ribeira, Km 111, CP 319, CEP 83411-000, Colombo, PR, maeda@cnpf.embrapa.br; helton@cnpf.embrapa. \\ br; bellote@cnpf.embrapa.br
}

\begin{abstract}
Resumo - A aplicação de resíduos celulósicos em plantios florestais resolve o problema de descarte, porém são necessários estudos que comprovem a segurança dessa forma de disposição. Avaliou-se a resposta de Pinus taeda L. à salinidade, em NEOSSOLO LITÓLICO Húmico. No plantio, avaliaram-se a altura e diâmetro do caule (DC) das mudas e, aos 120 dias de cultivo, avaliaram-se a altura, o DC, a biomassa seca das raízes (MSR), parte aérea (MSPA) e total (MST). Baseados nos teores de P, K, Ca, Mg e Na, estimaram-se as suas quantidades acumuladas e suas eficiências de utilização nas acículas e raízes e a translocação para a parte aérea. Exceto a razão da relação MSPA/MSR, as demais variáveis foram influenciadas pelo aumento da salinidade, com efeitos diferenciados entre as mesmas. Enquanto o DC e o seu incremento e a MSPA foram reduzidas apenas no tratamento com a maior condutividade elétrica (CE), a altura e o seu incremento apresentaram tendência de redução a partir da CE 3,28 dS m${ }^{-1}$ e a MSR e a MST a partir da CE $0,55 \mathrm{dS} \mathrm{m}^{-1}$. A eficiência de utilização do Pe do $\mathrm{Mg}$ diminuíram, enquanto a do $\mathrm{K}$ e do Ca não foram alteradas. A translocação dos nutrientes não foi alterada.
\end{abstract}

Termos para indexação: Condutividade elétrica, crescimento vegetal, eficiência de utilização.

\section{Biometric characteristics and seedlings nutrition of Pinus taeda under salinity stress at Humic Distrocryept}

\begin{abstract}
The application of cellulosic waste in forest plantations is an alternative to disposal, but more studies are necessary to confirm the safity of this disposal. The response of Pinus taeda L. to salinity in Humic Distrocryept was evaluated. In plantation, the seedlings were assessed for their height and stem diameter (SD), and at 120 days, were assessed the SD, height, dried root biomass (DRB), shoot (DBS) and total dried matter (TDM). The contents of $\mathrm{P}, \mathrm{K}, \mathrm{Ca}, \mathrm{Mg}$ and $\mathrm{Na}$ were determinated, and, based on these levels it was estimated the quantity of these elements and calculated the efficiency use in leaves and roots and translocation to the shoot. Except the relationship between DSB/DRB, the other variables were significantly influenced by increased salinity with different effects among them. While the SD and its increase and DSP were reduced only in treatment at the more high electric conductivity (EC), the height of the seedlings and the increment tended to reduce from EC of $3.28 \mathrm{dS} \mathrm{m}^{-1}$ and DRB and TDM from the EC $0.55 \mathrm{dS} \mathrm{m}^{-1}$. The efficiency of $\mathrm{P}$ and $\mathrm{Mg}$ utilization decreased while $\mathrm{K}$ and $\mathrm{Ca}$ did not alter. The translocation of nutrients was not altered.
\end{abstract}

Index terms: Electric conductivity, plant growth, nutritional efficiency.

\section{Introdução}

O desenvolvimento socioeconômico do Brasil tem tido expressiva contribuição do setor florestal. Em 2007 esse setor foi responsável pela geração de um produto interno bruto superior a US $\$ 44,6$ bilhões, o que equivale a 3,4\% do PIB nacional (SOCIEDADE BRASILEIRA DE SILVICULTURA, 2008). No segmento de florestas plantadas em 2007, o sistema Agroindustrial Florestal gerou aproximadamente 4,6 milhões de empregos incluindo 656 mil diretos, 1,8 milhão indiretos e
2,1 milhões empregos resultantes do efeito-renda (SOCIEDADE BRASILEIRA DE SILVICULTURA, 2008). Dentro do setor florestal, a produção de papel e celulose ocupa lugar de destaque, colocando o país entre os principais produtores mundiais.

O Pinus taeda L. é a segunda espécie florestal mais plantada no Brasil, com predomínio do seu plantio ocorrendo na Região Sul do Brasil (SOCIEDADE BRASILEIRA DE SILVICULTURA, 2008). A espécie é plantada para a produção de celulose, madeira para movelaria, geração de energia e outros fins. 
A geração de resíduos é consequência dos processos de transformação de matérias-primas. Um dos grandes desafios das indústrias de celulose e papel é a destinação final dos resíduos, hoje dispostos em aterros industriais. Essa alternativa é onerosa e gera uma responsabilidade pela sua guarda, que pode se eternizar, resultando num custo permanente.

Em função da sua composição química, os resíduos resultantes do processamento da madeira podem ter potencial de utilização comercial, porém, é necessário o pleno conhecimento de suas características, principalmente de seus efeitos no ambiente. O lodo celulósico, resultante do processo de tratamento de efluentes das indústrias de celulose e papel, apresenta teores consideráveis de $\mathrm{N}$ e P. Esses teores potencializam esse resíduo como sucedâneo de fertilizantes industrializados. No entanto, dados preliminares de pesquisa, avaliando o efeito de doses desse resíduo em Pinus taeda (0, 40, 80 e $\left.160 \mathrm{Mg} \mathrm{ha}^{-1}\right)$, em condições de vaso, mostraram efeitos prejudiciais do lodo, sendo apontado como uma das possíveis causas a salinidade resultante da presença de sais, entre os quais o $\mathrm{Na}$, remanescente dos produtos utilizados para extração da celulose da madeira. Nesse estudo, o sintoma inicial apresentado pelas plantas foi a seca das acículas inferiores a partir do seu ápice, com posterior morte das plantas nas doses mais elevadas do resíduo.

$\mathrm{O} \mathrm{NaCl}$ reduz a absorção e o transporte de elementos químicos essenciais ao crescimento e ao desenvolvimento das plantas (Noble \& Rogers, 1992). Estudos sobre os efeitos do sódio em espécies arbóreas são relatados por Ferreira et al. (2001), Silva et al. (2000), Mendonça et al. (2007), Santos \& Souza (2003) e Marinho et al. (2006). Em espécies anuais, o efeito negativo da salinidade foi observado por Dantas et al. (2002), Amorim et al. (2002), Carmo et al. (2003). Os efeitos da salinidade sobre as plantas podem resultar em seca fisiológica provocada pela redução do potencial osmótico; desequilíbrio nutricional provocado pela elevada concentração iônica e a inibição da absorção de outros cátions pelo sódio; e o efeito tóxico do sódio e cloro (Jeffrey \& Izquierdo, 1989). Após a absorção pelas raízes, $\mathrm{o} \mathrm{Na}^{+}$é transportado para a parte aérea da planta, onde pode provocar a queima das folhas (Rhoades \& Loveday, 1990).

Considerando a necessidade de conhecer os efeitos de componentes do lodo celulósico, conduziu-se esse trabalho com o objetivo avaliar o efeito de doses de $\mathrm{NaCl}$ sobre o desenvolvimento e a absorção de nutrientes por mudas de Pinus taeda.

\section{Material e Métodos}

O estudo foi conduzido em casa de vegetação não climatizada da Embrapa Florestas, em Colombo, PR, no período de novembro de 2008 a março de 2009 , totalizando 120 dias de crescimento das plantas.

As parcelas experimentais foram constituídas de sacos plásticos preenchidos com 4,35 $\mathrm{kg}$ de um Neossolo Litótico húmico, coletado na camada de $10 \mathrm{~cm}$ a $30 \mathrm{~cm}$, no município de Piraí do Sul, PR, o qual apresentava as seguintes características (Silva, 1999): $\mathrm{pH} \mathrm{em} \mathrm{CaCl}_{2}=$ 3,88; carbono orgânico $=15,94 \mathrm{~g} \mathrm{dm}^{-3} ; \mathrm{P}=1,65 \mathrm{mg} \mathrm{dm}^{-3}$; $\mathrm{K}=0,04 \mathrm{cmol}_{\mathrm{c}} \mathrm{dm}^{-3} ; \mathrm{Ca}=0,10 \mathrm{cmol}_{\mathrm{c}} \mathrm{dm}^{-3} ; \mathrm{Mg}=0,20$ $\mathrm{cmol}_{\mathrm{c}} \mathrm{dm}^{-3} ; \mathrm{Al}=2,63 \mathrm{cmol}_{\mathrm{c}} \mathrm{dm}^{-3} ; \mathrm{H}+\mathrm{Al}=8,36 \mathrm{cmol}_{\mathrm{c}}$ $\mathrm{dm}^{-3} ; \mathrm{V}=3,9 \% ; \mathrm{m}=88,8 \% ;$ areia $=759 \mathrm{~g} \mathrm{~kg}^{-1} ;$ silte $=55$ $\mathrm{g} \mathrm{kg}^{-1}$ e argila $=186 \mathrm{~g} \mathrm{~kg}^{-1}$. Após secagem, peneiramento e homogeneização, porções da amostra do solo foram colocadas nos recipientes. As mudas utilizadas foram produzidas com sementes originadas de árvores clonais de primeira geração e a semeadura foi feita em tubetes de $50 \mathrm{~cm}^{3}$, preenchidos com substrato comercial para pínus, sendo de 5 meses o período de produção das mudas no viveiro. O manejo das mudas foi realizado segundo o protocolo de produção adotado no viveiro.

Os tratamentos constituídos de doses de $\mathrm{Na}$, na forma de $\mathrm{NaCl}$ p.a. foram equivalentes a $0 ; 78 ; 156$; $625 ; 1.251$ e $2.502 \mathrm{mg}$ de $\mathrm{NaCl} \mathrm{kg}{ }^{-1}$ de solo, aplicados sob delineamento estatístico inteiramente ao acaso com quatro repetições. Avaliadas com base na incubação prévia durante 20 dias, em umidade correspondente a $80 \%$ da capacidade de campo, as doses aplicadas resultaram em condutividade elétrica de 0,$18 ; 0,55$; 1,$03 ; 3,28 ; 6,00$ e $12,3 \mathrm{dS} \mathrm{m}^{-1}$, respectivamente, a cada concentração estudada, determinada pelo método do extrato saturação (Raij et al., 2001). As alíquotas de $\mathrm{NaCl}$, equivalentes às doses estudadas, foram dissolvidas em água destilada, em volume suficiente para atingir $80 \%$ da capacidade de campo, sendo o teor de água mantido nesse nível até o final do período de condução do estudo pela aplicação de água destilada, e o volume necessário avaliado pela pesagem do material de cada parcela. 


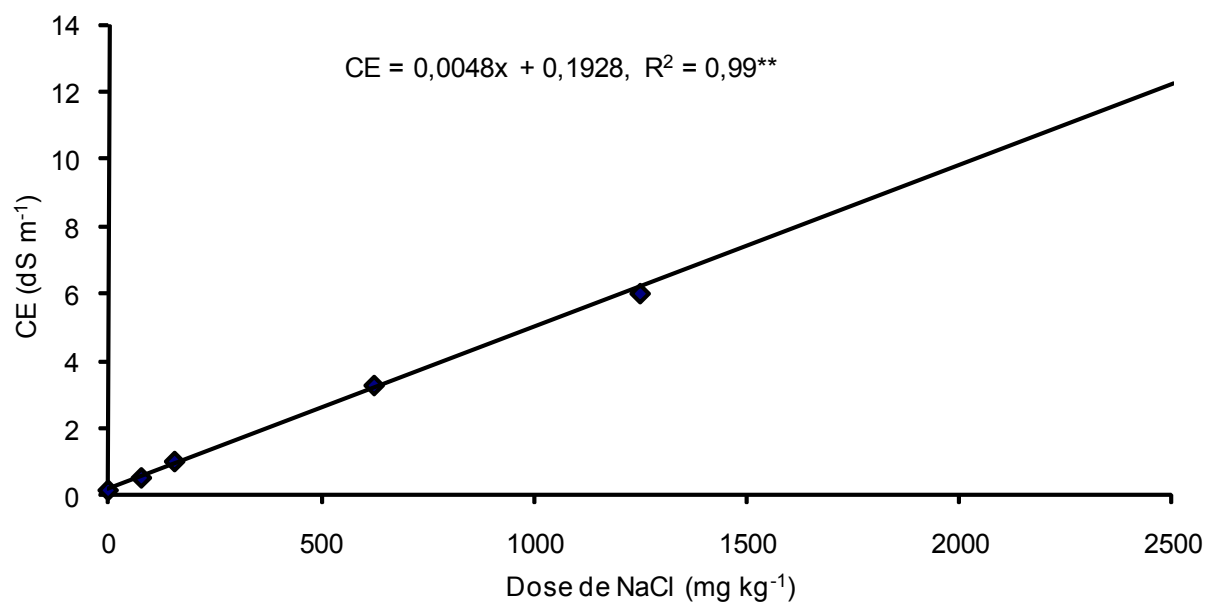

Figura 1.Condutividade elétrica (CE) resultante da aplicação de doses de $\mathrm{NaCl}$, utilizando como fonte o $\mathrm{NaCl}$ em trabalho prévio de incubação durante 20 dias em Neossolo Litólico húmico.

Foram realizadas avaliações de altura e diâmetro do caule ao nível do solo (DC) das mudas no dia do plantio e aos 120 dias após a implantação, obtendo-se o incremento dessas características no período avaliado. Após essa avaliação, a planta foi cortada ao nível do solo para separação da parte aérea das raízes. Em seguida, todo o material coletado foi lavado com água destilada e seco em estufa a aproximadamente $65^{\circ} \mathrm{C}$ com circulação de ar forçada, por 48 horas para obtenção da biomassa seca das diferentes partes.

A biomassa seca das raízes, caule e acículas foram submetidas à análise química e determinados os teores de $\mathrm{P}, \mathrm{K}, \mathrm{Ca}$ e Mg (Silva, 1999). A quantidade de nutrientes acumuladas na biomassa foi determinada com base em seus respectivos teores. Foram estimados índices de utilização de nutrientes na biomassa seca das acículas (EUacículas) e das raízes (EUraízes), conforme Siddiqi \& Glass (1981) e índices de translocação de nutrientes para a parte aérea $(\mathrm{T})$, com base nas seguintes equações (Silva et al. , 2000):

EUacículas $=$ MSacículas ${ }^{2} /$ nutrientes acumulados na MSacículas, em $\mathrm{g}^{2} \mathrm{mg}^{-1}$;

EUraízes $=$ MSraízes ${ }^{2} /$ nutrientes acumulados na MSraízes, em g $\mathrm{mg}^{-1} \mathrm{e}$,

$\mathrm{T} \%=$ (nutriente acumulado na (MSacículas + MScaule))/nutriente total acumulado na planta) x 100 .

Para avaliar o efeito dos diferentes níveis de salinidade provocado pela aplicação de doses de $\mathrm{Na}$ nas variáveis estudadas, os dados obtidos foram submetidos à análise de variância $(\alpha=0,05)$ e ao teste de Tukey, no mesmo nível de probabilidade. Às variáveis com valor de $\mathrm{F}$ significativo foram ajustadas funções que as relacionaram aos efeitos da salinidade.

\section{Resultados e Discussão}

De modo geral, todas as características biométricas avaliadas foram estatisticamente influenciadas pelo aumento da salinidade provocada pela aplicação de doses de $\mathrm{NaCl}$ (Tabela 1). No entanto, o efeito em cada variável dependeu do nível de salinidade, avaliado pela condutividade elétrica (CE), resultante da aplicação do produto utilizado.

A altura final e o incremento em altura não foram influenciados até a CE de $1,03 \mathrm{dS} \mathrm{m}^{-1}$, proporcionada pela aplicação de $156 \mathrm{mg}$ de $\mathrm{NaCl} \mathrm{kg}^{-1}$ de solo. $\mathrm{NaCE}$ de 3,28 dS m${ }^{-1}$, resultante da aplicação de $625 \mathrm{mg}$ de $\mathrm{NaCl} \mathrm{kg}{ }^{-1}$ de solo, a altura final e o incremento em altura foram significativamente reduzidos. Nesse tratamento, a redução no crescimento em altura, em relação à dose 0 foi de $10 \%$ (Figura 2). A menor altura e o menor incremento em altura foram observados na maior $\mathrm{CE}$, o que correspondeu a uma redução de $35 \%$ na altura e $80 \%$ no incremento. O comportamento observado no incremento em altura foi linear e decrescente, como pode ser observado na Figura 3. 
Tabela 1. Altura final e incremento em altura, diâmetro do caule (DC) final e incremento no DC e biomassas secas da raiz (MSR), parte aérea (MSPA) e total (MST) e relação MSPA/MSR de mudas de Pinus taeda avaliada aos 120 dias após plantio, em função da condutividade elétrica (CE) resultantes da aplicação de doses de $\mathrm{NaCl}(0 ; 78 ; 156 ; 625 ; 1.251 \mathrm{e}$ $2.502 \mathrm{mg}$ de $\mathrm{NaCl} \mathrm{kg}{ }^{-1}$ de solo).

\begin{tabular}{|c|c|c|c|c|c|c|c|c|}
\hline $\mathbf{C E}$ & $\begin{array}{c}\text { Altura } \\
\text { final }\end{array}$ & $\begin{array}{c}\text { Incremento } \\
\text { em altura }\end{array}$ & DC final & $\begin{array}{c}\text { Incremento } \\
\text { DC }\end{array}$ & MSR & MSPA & MST & MSPA/MSR \\
\hline dS.m $m^{-1}$ & \multicolumn{2}{|c|}{$(\mathrm{cm})$} & \multicolumn{2}{|c|}{$(\mathrm{mm})$} & \multicolumn{3}{|c|}{ (g) } & - \\
\hline 0,18 & $44,8 * \mathrm{a}$ & $19,7 \mathrm{a}$ & $5,93 \mathrm{a}$ & $3,1 \mathrm{a}$ & $2,27 \mathrm{a}$ & $7,12 \mathrm{a}$ & $9,39 \mathrm{a}$ & $3,17 \mathrm{a}$ \\
\hline 0,55 & $43,0 \mathrm{a}$ & $18,0 \mathrm{a}$ & $5,90 \mathrm{a}$ & $3,2 \mathrm{a}$ & $2,01 \mathrm{ab}$ & $6,94 \mathrm{a}$ & $8,95 \mathrm{ab}$ & $3,46 \mathrm{a}$ \\
\hline 1,03 & $43,9 \mathrm{a}$ & $18,8 \mathrm{a}$ & $5,86 \mathrm{a}$ & $3,2 \mathrm{a}$ & $1,63 \mathrm{bc}$ & $6,20 \mathrm{a}$ & $7,83 \mathrm{ab}$ & $3,86 \mathrm{a}$ \\
\hline 3,28 & $41,3 \mathrm{ab}$ & $16,3 \mathrm{ab}$ & $5,85 \mathrm{a}$ & $3,3 \mathrm{a}$ & $1,56 \mathrm{bc}$ & $6,28 \mathrm{a}$ & $7,83 \mathrm{ab}$ & $4,09 \mathrm{a}$ \\
\hline 6,00 & $35,0 \mathrm{bc}$ & $9,4 \mathrm{bc}$ & $5,77 \mathrm{a}$ & $2,6 \mathrm{a}$ & $1,33 \mathrm{c}$ & $5,58 \mathrm{a}$ & $6,91 \mathrm{~b}$ & $4,18 \mathrm{a}$ \\
\hline 12,30 & $29,6 \mathrm{c}$ & $4,0 \mathrm{c}$ & $4,06 \mathrm{~b}$ & $1,1 \mathrm{~b}$ & $0,65 \mathrm{~d}$ & $2,88 \mathrm{~b}$ & $3,53 \mathrm{c}$ & $4,48 \mathrm{a}$ \\
\hline CV - \% & 9,26 & 24,77 & 17,87 & 14,44 & 15,70 & 12,81 & 12,22 & 15,50 \\
\hline
\end{tabular}

* Valores nas colunas seguidos por letras iguais não diferem significativamente pelo teste de Tukey $5 \%$.

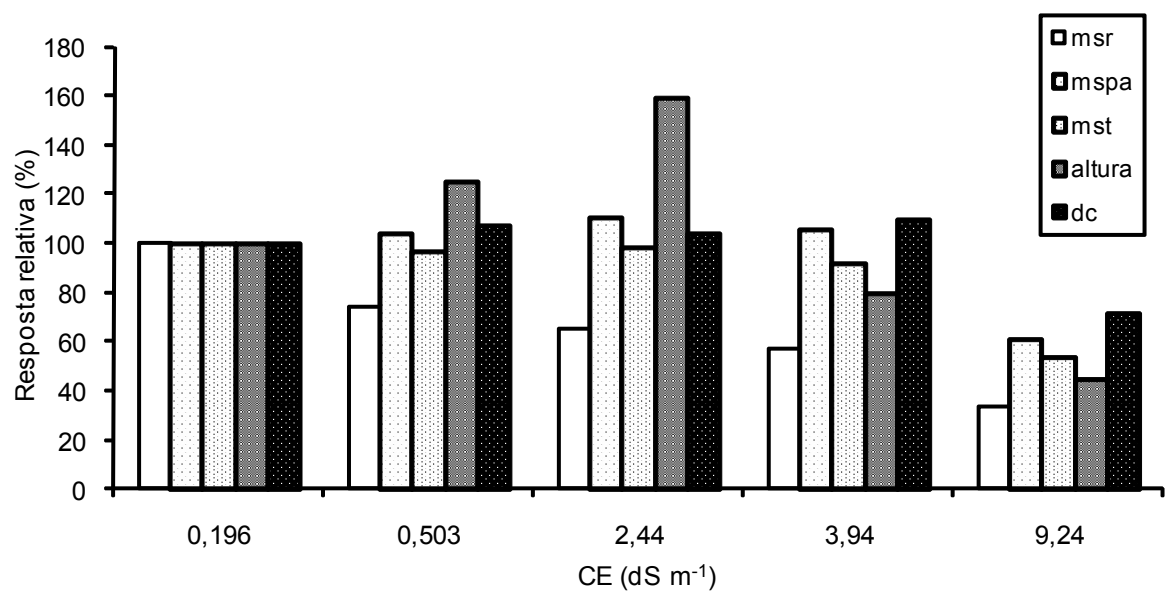

Figura 2. Resposta relativa de mudas de Pinus taeda, submetidas a diferentes doses de $\mathrm{NaCl}$, avaliadas pela biomassa seca das raízes (msr), da parte aérea (mspa) e total (mst), altura da planta (alt) e diâmetro do caule (dc).

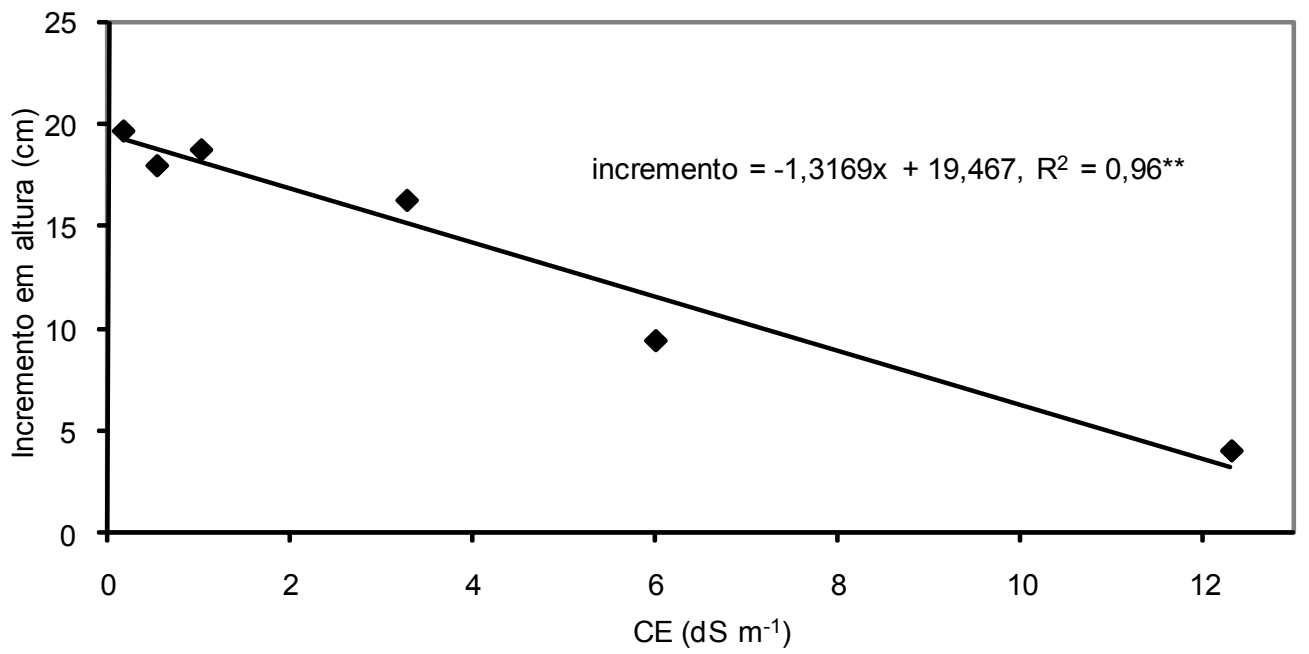

Figura 3. Incremento em altura de mudas de Pinus taeda em resposta a alterações na condutividade elétrica (CE) da solução de um Neossolo Litólico húmico promovidas pela aplicação de doses de $\mathrm{NaCl}$. 
Com relação ao diâmetro do caule (DC) final e ao incremento no DC, o efeito foi significativo apenas no maior nível de salinidade, indicando, possivelmente, uma menor sensibilidade dessa característica ao aumento da salinidade. O comportamento em termos de DC foi representado por uma regressão quadrática negativa, em relação ao aumento da CE da solução do solo (Figura 4).

A biomassa seca de raízes apresentou tendência de redução a partir da $\mathrm{CE} 0,55 \mathrm{dS} \mathrm{m}^{-1}$, resultante da aplicação de $78 \mathrm{mg}$ de $\mathrm{NaCl} \mathrm{kg}{ }^{-1}$ de solo. As reduções foram crescentes com o aumento da salinidade do solo (Tabela 1), sendo essa característica a mais influenciada pelo aumento da salinidade. A biomassa seca da parte aérea foi reduzida apenas no maior nível de salinidade do solo, enquanto a biomassa seca total mostrou tendência de redução a partir da segunda dose $\left(\mathrm{CE} 0,55 \mathrm{dS} \mathrm{m}^{-1}\right)$, como resultado do efeito observado na biomassa seca das raízes. No maior nível de salinidade do solo, a biomassa seca total correspondeu a $62 \%$ do observado no tratamento onde o $\mathrm{NaCl}$ não foi aplicado.

A razão da relação entre a biomassa seca da parte aérea e das raízes é frequentemente avaliada em estudos do efeito de estresse salino (Melloni et al., 2000; Silva et al., 2000 e Ferreira et al., 2001). Apesar dos efeitos observados nas biomassas secas da raiz e da parte aérea, a razão entre essas variáveis não foi influenciada pelo aumento da salinidade promovida pela aplicação de $\mathrm{NaCl}$, ao contrário do observado por Melloni et al. (2000) e Silva et al. (2000), ambos em aroeira e Ferreira et al. (2001) em goiabeira.

$\mathrm{O}$ efeito da salinidade promovido pelo $\mathrm{NaCl}$ sobre as plantas tem sido o objetivo de outros estudos (Silva et al., 2000; Santos \& Souza, 2003; Marinho et al., 2006; Mendonça et al., 2007; Nunes et al., 2008). É consenso que no estresse osmótico, toxicidade por excesso de íons, principalmente $\mathrm{Na}$ e $\mathrm{Cl}$, e o desequilíbrio nutricional provocado pela salinidade interferem no crescimento das plantas (Marschner, 1995). Conforme Tomé Jr. (1997), o excesso de sais na zona radicular pode prejudicar a germinação, o desenvolvimento e a produtividade das plantas, como consequência do maior gasto energético para absorver água, energia essa desviada de processos metabólicos essenciais. Além disso, o aumento da concentração salina pode promover um desequilíbrio nutricional devido ao aumento da concentração iônica e à inibição da absorção de outros cátions pelo $\mathrm{Na} \mathrm{e}$ mesmo o efeito tóxico dos íons sódio e cloreto (Salisbury \& Ross, 1991).

Embora o efeito salino seja prejudicial ao crescimento de muitas espécies de plantas, existem aquelas classificadas como halófilas, para as quais o $\mathrm{Na}$ tem efeito benéfico (Marschner, 1995). Tais espécies apresentam a capacidade de promover o equilíbrio osmótico com a solução do solo, acumulando os íons absorvidos no vacúolo das células, o que parece não ser o caso do Pinus taeda, uma vez que com CE de $0,55 \mathrm{dS}$ $\mathrm{m}^{-1}$, observou-se uma tendência de redução na biomassa seca das raízes e total.

Considerando que, para efeitos pedológicos, a partir da CE de 4,0 dS m ${ }^{-1}$ até $7 \mathrm{dS} \mathrm{m}^{-1}$, o solo é considerado como salino (Santos et al., 2006), com base na resposta observada, o cultivo de Pinus taeda nas condições de um solo salino poderia sofrer restrições no seu desenvolvimento.

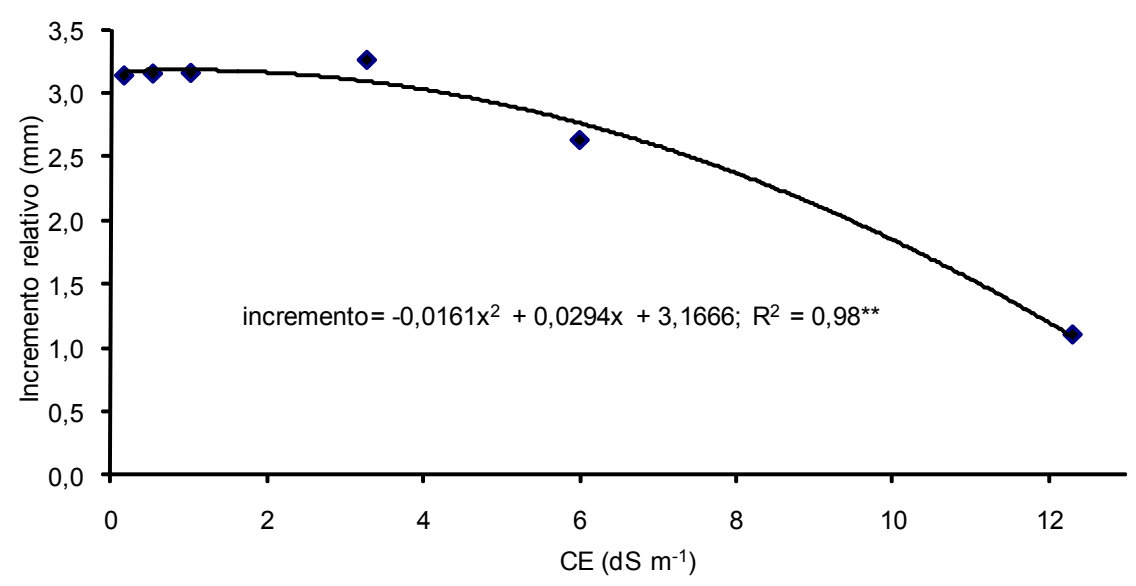

Figura 4. Incremento em diâmetro do caule (DC) de mudas de Pinus taeda em resposta a alterações na condutividade elétrica (CE) da solução de um Neossolo Litólico húmico promovidas pela aplicação de doses de $\mathrm{NaCl}$. 
Com relação aos nutrientes, observou-se que o acúmulo de fósforo foi influenciado apenas nas raízes, ocorrendo uma redução no seu teor com o aumento da CE. O acúmulo de $\mathrm{K}$ nas acículas apresentou um comportamento quadrático, enquanto nos demais compartimentos não houve efeito do aumento da $\mathrm{CE}$ (Figura 5). Em relação ao $\mathrm{Ca}$ e ao $\mathrm{Mg}$, o aumento da CE reduziu o acúmulo desses nutrientes em todos os compartimentos analisados. As reduções observadas nas quantidades acumuladas de $\mathrm{P}, \mathrm{Ca}$ e $\mathrm{Mg}$, provavelmente, estão associadas ao decréscimo de produção de biomassa seca, o que está de acordo com os resultados obtidos por Silva et al. (2000) e Miranda \& Carvalho (1998) trabalhando com aroeira - Myracrodruon urundeuva. Com relação ao acúmulo de $\mathrm{Na}$, o comportamento observado nos compartimentos avaliados foi quadrático, com o pico de acúmulo variando entre os mesmos (Figura 6), provavelmente, como reflexo da redução na produção de biomassa.
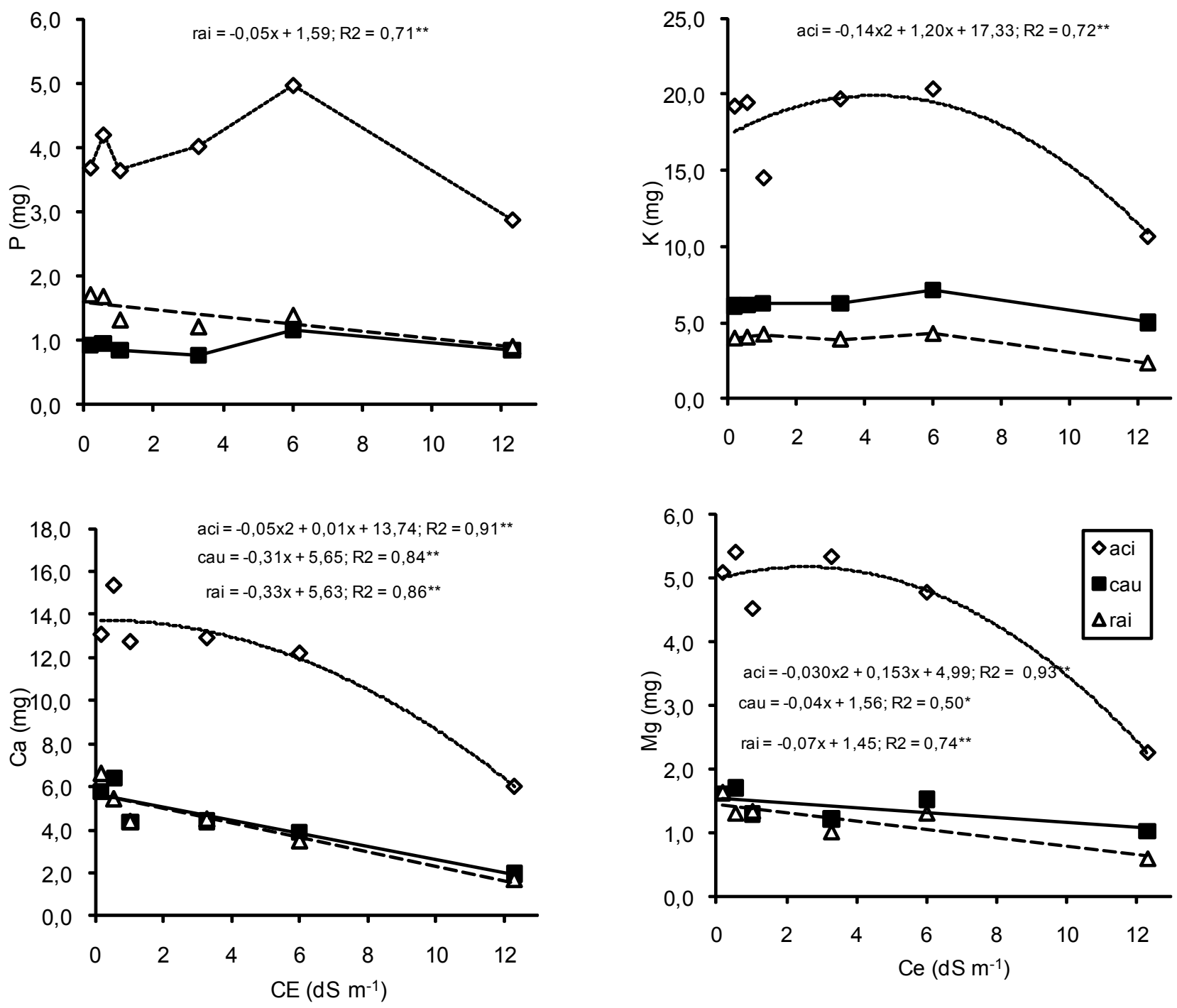

Figura 5. Alterações no acúmulo de nutrientes nas acículas (aci), caule (cau) e raízes (Raí) em função de alterações na condutividade elétrica (CE) da solução de um NEOSSOLO LITÓLICO Húmico promovidas pela aplicação de doses de NaCl. 


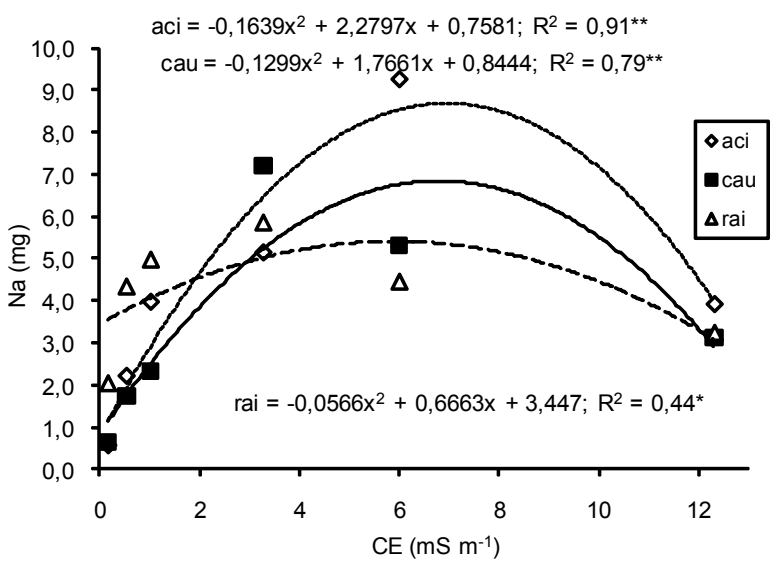

Figura 6. Relação entre acúmulo de Na no caule (cau), acículas (aci) e raízes (rai) de mudas de Pinus taeda, em função da alteração da condutividade elétrica (CE) do solo, promovidas pela aplicação de doses de $\mathrm{NaCl}$ em Neossolo Litólico húmico.

A porcentagem de translocação dos nutrientes avaliados para a parte aérea foi elevada, independentemente da dose de $\mathrm{Na}$ aplicada (Tabela 2), indicando que, provavelmente, esse processo não foi alterado pela elevada concentração de $\mathrm{NaCl}$. Com relação ao $\mathrm{Na}$, observou-se um aumento na translocação até a CE de $6,3 \mathrm{dS} \mathrm{m}^{-1}$, seguida de uma redução no valor maior da $\mathrm{CE}\left(12,3 \mathrm{dS} \mathrm{m}^{-1}\right)$.

Com relação à eficiência na utilização de nutrientes avaliada nos compartimentos estudados, observouse que a do $\mathrm{K}$ e a do $\mathrm{Ca}$ não foram influenciadas em quaisquer dos compartimentos. Por sua vez, a eficiência do $\mathrm{P}$ foi alterada nos dois compartimentos avaliados, observando-se um comportamento de redução da eficiência como resultado do aumento da salinidade do solo com o aumento da dose aplicada (Tabela 2 e Figura 7). A eficiência de utilização do $\mathrm{Mg}$ nas raízes foi reduzida com o aumento da salinidade do solo promovida pela aplicação das doses de $\mathrm{NaCl}$. Esses dados corroboram a inibição na absorção de nutrientes provocada pelo $\mathrm{Na}$, como observado por Silva et al. (2000) em aroeira.

As acículas não apresentaram sintomas visuais de danos provocados pela aplicação de $\mathrm{Na}$ no período estudado.

Tabela 2. Eficiência de utilização dos nutrientes nas acículas (EUacicula) e nas raízes (EUraiz) e índice de translocação de nutrientes $(\mathrm{T})$ em função da alteração da condutividade elétrica (CE) do solo promovida pela aplicação de doses de $\mathrm{NaCl}$ em Neossolo Litólico húmico.

\begin{tabular}{|c|c|c|c|c|c|}
\hline \multirow{2}{*}{$\frac{C E}{d S ~ m^{-1}}$} & \multicolumn{5}{|c|}{ EUacícula $\left(\mathrm{g}^{2} \mathrm{mg}^{-1}\right)^{*}$} \\
\hline & $\mathbf{P}$ & $\mathbf{K}$ & $\mathbf{C a}$ & Mg & $\mathbf{N a}$ \\
\hline 0,18 & $5,30 \mathrm{a}$ & 0,72 & 28,51 & 34,08 & - \\
\hline 0,55 & $4,22 \mathrm{ab}$ & 0,92 & 25,93 & 47,60 & - \\
\hline 1,03 & $3,73 \mathrm{bc}$ & 0,93 & 17,26 & 36,20 & - \\
\hline 3,28 & $3,94 \mathrm{abc}$ & 0,83 & 31,10 & 32,39 & - \\
\hline 6,00 & $2,71 \mathrm{c}$ & 1,26 & 34,84 & 32,03 & - \\
\hline \multirow[t]{2}{*}{12,30} & $1,18 \mathrm{~d}$ & 0,81 & 21,57 & 16,46 & - \\
\hline & \multicolumn{5}{|c|}{ EUraiz $\left(\mathrm{g}^{2} \mathrm{mg}^{-1}\right)^{*}$} \\
\hline 0,18 & $3,01 \mathrm{a}$ & 0,76 & 2,46 & $27,05 \mathrm{a}$ & - \\
\hline 0,55 & $2,42 \mathrm{a}$ & 0,98 & 4,01 & $22,84 \mathrm{a}$ & - \\
\hline 1,03 & $2,04 \mathrm{ab}$ & 0,45 & 4,62 & $15,04 \mathrm{abc}$ & - \\
\hline 3,28 & $1,99 \mathrm{ab}$ & 0,42 & 3,71 & $19,94 \mathrm{ab}$ & - \\
\hline 6,00 & $1,28 \mathrm{bc}$ & 0,47 & 5,54 & $9,52 \mathrm{bc}$ & - \\
\hline \multirow[t]{2}{*}{12,30} & $0,47 \mathrm{c}$ & 0,43 & 3,73 & $5,06 \mathrm{c}$ & - \\
\hline & \multicolumn{5}{|c|}{$\mathrm{T}(\%) *$} \\
\hline 0,18 & 72,85 & 86,45 & 74,20 & 80,32 & $38,59 \mathrm{~b}$ \\
\hline 0,55 & 74,71 & 85,53 & 79,24 & 84,28 & $44,93 \mathrm{ab}$ \\
\hline 1,03 & 77,33 & 82,98 & 80,05 & 81,72 & $53,95 \mathrm{ab}$ \\
\hline 3,28 & 79,72 & 86,95 & 79,46 & 86,63 & $65,50 \mathrm{ab}$ \\
\hline 6,00 & 80,66 & 86,18 & 82,09 & 82,32 & $76,19 \mathrm{a}$ \\
\hline 12,30 & 80,18 & 87,16 & 81,88 & 84,85 & $65,39 \mathrm{ab}$ \\
\hline
\end{tabular}

(-) não determinado

* médias seguidas pelas mesmas letras não diferem significativamente entre si (Tukey, 5\%). 


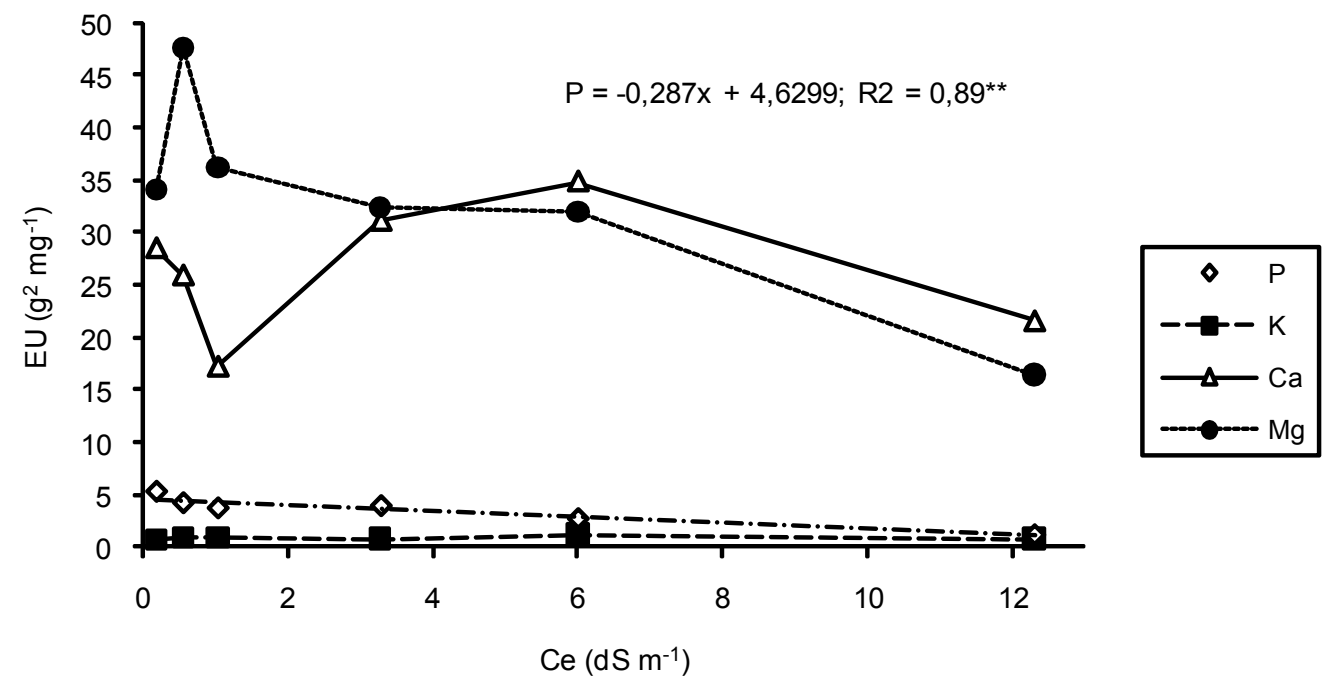

Figura 7.Índices de eficiência de utilização de nutrientes nas acículas (EUaci) e nas raízes (EUraiz) de mudas de Pinus taeda, em função da alteração da condutividade elétrica (CE) do solo, promovidos pela aplicação de doses de $\mathrm{NaCl}$ em Neossolo Litólico húmico.

\section{Conclusões}

As mudas de Pinus taeda mostram sensibilidade à aplicação de $\mathrm{NaCl}$.

As variáveis biométricas avaliadas apresentam sensibilidade diferenciada ao aumento da salinidade do solo. A biomassa seca das raízes diminui a partir da $\mathrm{CE}=0,55 \mathrm{dS} . \mathrm{m}^{-1}$; altura da muda reduz a partir de 6,3 $\mathrm{dS} \mathrm{m} \mathrm{m}^{-1}$ e o diâmetro de colo e a biomassa seca da parte aérea foram reduzidas apenas na maior $\mathrm{CE}\left(12,0 \mathrm{dS} \mathrm{m}^{-1}\right)$.

$\mathrm{O} \mathrm{NaCl}$ reduz os índices de eficiência do $\mathrm{P}$ e do $\mathrm{Mg}$ e não altera os índices de eficiência do $\mathrm{K}$ e do $\mathrm{Ca}$.

$\mathrm{O}$ aumento na salinidade promovida pela aplicação de $\mathrm{NaCl}$ altera a translocação de $\mathrm{P}, \mathrm{K}, \mathrm{Ca}$ e Mg.

\section{Referencias}

AMORIM, J. R. A.; FERNANDES, P. D.; GHEYI, H. R. Efeito da salinidade e modo de aplicação da água de irrigação no crescimento e produção de alho. Pesquisa Agropecuária Brasileira, v.37, n.2, p. 167-176, 2002.

CARMO, G. A.; MEDEIROS, J. F.; TAVARES, J. C. Crescimento de bananeiras sob diferentes níveis de salinidade da água de irrigação. Revista Brasileira de Fruticultura, v.25, n. 3, p. 513518, 2003.

DANTAS, J. P.; MARINHO, F. J. L.; FERREIRA, M. M. M. Avaliação de genótipos de caupi sob salinidade. Revista Brasileira de Engenharia Agrícola e Ambiental, v.6, n.3, p. 425-430, 2002.
FERREIRA, R.G.; TAVORA, F. J. A. F.; HERNANDEZ, F. F. F. Distribuição da matéria seca e composição química das raízes, caule e folhas de goiabeira submetida a estresse salino. Pesquisa Agropecuária Brasileira, v. 36, n. 1, p. 79-88, 2001.

JEFFREY, W.D.; IZQUIERDO, J. Frijol: fisiologia del potencial del rendimiento y la tolerância al estresé. Santiago: FAO, 1989. $91 \mathrm{p}$.

MARINHO, F. J. L.; GHEVY, H. R.; FERNANDES, P. D.; HOLANDA, J. S. de; FERREIRA NETO, M. Cultivo de coco "Anão Verde" irrigado com águas salinas. Pesquisa Agropecuária Brasileira. Brasília, v. 41, n. 8, p. 1277-1284, 2006.

MARSCHNER, H. Mineral nutrition of higher plants. 2. ed., London: Academic Press, 1995. 889p.

MELLONI, R.; SILVA, F. A. M.; CARVALHO, J. G. de. Cálcio, magnésio e potássio como amenizadores dos efeitos da salinidade sobre a nutrição mineral e o crescimento de mudas de aroeira (Myracorduon urundeuva). Cerne, v. 6, n. 2, p. 35-40, 2000.

MENDONÇA, A. V. R.; CARNEIRO, J. G. de A.; BARROSO, D. G.; SANTIAGO, A. R.; RODRIGUES, L. A. R.; FREITAS, T. A. S. de. Características biométricas de mudas de Eucalyptus $s p$. sob estresse salino. Revista Árvore, Viçosa, MG, v.31, n.3, p. 365-372, 2007

MIRANDA, J.R.P.; CARVALHO, J.G. Efeito do $\mathrm{NaCl}$ e do $\mathrm{SiO}_{2}$ sobre o crescimento e a nutrição mineral de plantas de aroeira (Myracrodruon urundeuva). In: REUNIÃO BRASILEIRA DE MANEJO E CONSERVAÇÃO DO SOLO E DA ÁGUA: AGRICULTURA E SUSTENTABILIDADE NO SEMI-ÁRIDO, 12., 1998, Fortaleza. Resumos expandidos... Fortaleza: UFC/ DCS, 1998. p.132. 
NOBLE, C. L.; ROGERS, M. E. Arguments for the use of physiological criteria for improving the salt tolerance in crops. Plant and Soil, v. 146, n. 1/2, p. 99-107, 1992.

NUNES, W. A. G. de A.; KER, J. C.; NEVES, J. C. L.; RUIZ, H. A.; BEIRIGO, R. M.; BONCOMPANI, A. L. P. Características químicas de solos da região de Janaúba, MG, irrigados com água de poços tubulares e do rio Gorutuba. Revista Brasileira de Ciência do Solo, v.32, n.1, p. 227-236, 2008.

RAIJ, B. van; GHEYI, H. R.; BATAGLIA, O. C. Determinação da condutividade elétrica e de cátions solúveis em extratos aquosos de solos. 2001. In: RAIJ, B. van; ANDRADE, J. C. de; CANTARELlA, H.; QUAGGIO, J. A. (Eds.) Análise química para avaliação da fertilidade de solos tropicais, Campinas, Instituto Agronômico, p. 277-284.

RHOADES, J. D.; LOVEDAY, J. Salinity in irrigated agriculture. In: STEWART, B. A.; NIELSEN, D. R. (Ed.). Irrigation of agricultural crops. Madison : American Society of Agronomy, 1990. p. 1089-1157. (ASA. Monograph, 30).

SALISBURY, F. B.; ROSS, C. W. Plant phisiology. 4 ed. Belmont, CA, EUA: Wadsworth Publishing Company, 1991. $682 \mathrm{p}$.

SANTOS, H.G dos; JACOMINE, P.K.T.; ANJOS, L.H.C.; OLIVEIRA, V.A. de; OLIVEIRA, J.B. de; COELHO, M.R.; LUMBRERAS, J.F.; CUNHA, T.J.F da (Ed.). Sistema brasileiro de classificação de solos. 2. ed. Rio de Janeiro: Embrapa Solos, 2006. 306p.

SANTOS, J. R. dos; SOUZA, R. F. Efeito do estresse salino no desenvolvimento inicial de mangueira (Mangifera indica L.).

Magistra, Cruz das Almas, BA, v. 15, n.1, p. 2003.
SIDDIQI, M.T.; GLASS, A.D.M. Utilization índex: a modified approach to the estimation and comparison of nutrient utilization efficiency in plants. Journal of Plant Nutrition, New York, v.4, p.289-302, 1981.

SILVA, F.C. (Org.). Manual de análises químicas de solos, plantas e fertilizantes. Brasília, DF: Embrapa Comunicação para Transferência de Tecnologia; Rio de Janeiro: Embrapa Solos; Campinas: Embrapa Informática Agropecuária, 1999. 370 p.

SILVA, F. A. de M.; MELLONI, R.; MIRANDA, J. R. P. de; CARVALHO, J. G. de. Efeito do estresse salino sobre a nutrição mineral e o crescimento de mudas de aroeira (Myracruodruon urundeura) cultivado em solução nutritiva. Cerne, v. 6, n. 1, p. 52-59, 2000.

SILVA, F. C. da (Org.). Manual de análises químicas de solos, plantas e fertilizantes. Brasília, DF: Embrapa Comunicação para Transferência de Tecnologia; Rio de Janeiro: Embrapa Solos; Campinas: Embrapa Informática Agropecuária, 1999. 370 p.

SOCIEDADE BRASILEIRA DE SILVICULTURA. Fatos e números do Brasil florestal, 2008. Disponível em http://www. sbs.org.br/fatosenumerosdobrasilflorestal.pdf. Consultado em 10/04/2010.

TOMÉ JUNIOR, J. B. Manual para interpretação de análises de solos. Guaíba: Gráfica e Editora Agropecuária, 1996. 148 p

Recebido em 28 de agosto de 2009 e aprovado em 08 de julho de 2010 
